\title{
Theory of mind as a proxy for Palaeolithic language ability
}

An alternative to the search for the earliest symbolic material culture

\author{
Cory Marie Stade \\ University of Southampton, Southampton, UK \\ c.stade@soton.ac.uk
}

\begin{abstract}
Symbolic artefacts have long been archaeology's primary contribution to tracing the origin and subsequent development of human language. But the identification and interpretation of symbolic behaviour poses numerous interpretive problems, particularly before the Upper Palaeolithic where clearly referential forms of symbolic material are rare. As an alternative, theory of mind is presented here, detailing its intimate relationship with language and likely coevolution, alongside the factors which make it a more effective proxy. As a cognitive ability that grades in complexity and predicts linguistic skill in modern cognition, theory of mind also has the potential to denote specific syntactic and semantic features of language such as word reference, mental state verbs and complementation. The potential to detect theory of mind in the archaeological record is considered here, such as within the cultural transmission of stone tool technology and forms of complex social learning like imitation and teaching in early hominin technologies.
\end{abstract}

\section{Keywords}

language evolution - theory of mind - symbolism - cultural transmission - social learning - imitation

\section{1 \\ Introduction}

The challenge of defining language is in incorporating everything it is, while excluding everything it is not (Aitchison, 2008). But broadly speaking and in its 
essence, language is a system of learned symbols shared by a community, where those symbols' purpose is to intentionally communicate. Assessing this multicomponent ability in our Palaeolithic ancestors is notoriously challenging. As often stressed in the literature, language is 'ephemeral', and therefore indirect indicators are needed to recognize it archaeologically (Jackendoff, 2002); conventional fossils that allow us to track its appearance and gradual evolution simply do not exist. The evolution of language has even been suggested to be the hardest problem in science (Christiansen and Kirby, 2003), because of the necessity of interaction (and cooperation) from so many disciplines, from comparative biology and psychology, to linguistics and genetics, and the difficulty of specializing in so many different fields.

From the contribution of archaeology, which represents the domain of hominin material culture, the most commonly used and best held indicator of language ability has thus far been the identification of symbolic behaviour from the presence of symbolic artefacts (d'Errico et al., 2003; Tattersall, 2017), of which the earliest examples date from the end of the Middle Palaeolithic/Middle Stone Age (approx. 115,000-50,000 years ago), and the Upper Palaeolithic/ Late Stone Age (approx. 50,000 to 10,000 years ago). A symbolic artefact is one in which a referential relationship is interpreted, in which the artefact stands for something else (Whitehead, 1927). This referential relationship is often identified by a perceived lack of utilitarian use for the artefact (Noble and Davidson, 1991; d'Errico, 1998; Henshilwood et al., 2001; Moncel et al., 2012; Půtová, 2016), to which researchers then interpret a sophisticated cultural system of meaning and information sharing, including cognitive and linguistic abilities (e.g. Davidson and Noble, 1989; Watts, 2009). By the Upper Palaeolithic, clear examples of representational figures and images such as cave paintings of animals more readily establish the referential nature of the items (Wynn et al., 2009). However, the often enigmatic representational phenomena of the Middle Palaeolithic and earlier, in addition to being exceedingly rare and hotly contested, mean that symbolism is difficult to interpret (e.g. d'Errico and Nowell, 200o; although, see Hoffman et al. (2018a) for a recent, more clearly representational example of Middle Palaeolithic cave art c. 65,000 years ago). While establishing a symbolic referential relationship is still challenging with many Upper Palaeolithic (or indeed later) artefacts, the problem is most pronounced in these earlier timeframes. Even though a number of language evolution researchers maintain that language's origins lie hundreds of thousands of years further back in time than these earliest symbolic artefacts suggest (Aiello and Dunbar, 1993; Bickerton, 2009; Corballis, 2011; Johansson, 2011; Dediu and Levinson, 2013; Lieberman, 2015; Everett, 2017), this symbolically focused paradigm for understanding language emergence is always doomed to 
TABLE 1 Problems with relying on symbolism to interpret cognitive and linguistic abilities in pre-Upper Palaeolithic populations, where few examples are clearly representational

Problem Detail

Poor mechanistic explanations There is great difficulty in demonstrating that an item was indeed symbolic to a Palaeolithic community, and determining what requirements objects must fulfil to be deemed symbolic.

Little analytical confidence There is a lack of explicit cognitive mechanisms detailing the requirements for symbolic thought and how these relate to language use.

Limited available evidence Pre-Upper Palaeolithic symbolic objects are rare, and cognitive interpretations from symbolic material cannot be made in geographic areas or timescales where symbolic material was not in use or has not been preserved, and the proxy is therefore limited to recent and localized spaces.

Binary interpretation The attribution of symbolism to an object allows only a 'presence or absence' interpretation, which results in a simple binary cognitive or linguistic interpretation that does not reflect the scaled complexity of cognitive abilities such as language.

portray a late characterisation of this most human ability, if symbolic material culture appears much later than language (a summary of this and other problems with the symbolic method of inferences of cognition and language can be seen in Table 1). Wynn and Coolidge (2010) call this sole focus on symbolism in cognitive archaeology a "failure", and note the paucity of interpretive concepts available to researchers. This paper therefore offers a novel interpretive concept that is hoped will expand and reinvigorate an important contributing discipline to the questions of language's origins.

The 'symbols to language' interpretation of Palaeolithic artefacts has a long history (Marshack, 1976; Chase and Dibble, 1987; Davidson and Noble, 1989; 
Henshilwood et al., 2001). This interpretation has been criticized, in addition to Wynn and Coolidge (2010), by Botha (2008, 2010), who takes the specific case of pierced shells from Blombos Cave, South Africa (Henshilwood et al., 2004; Henshilwood and Dubrueil, 2011). Pierced shells (interpreted as beads) remain the best candidate for the oldest examples of symbolic behaviour, extending back at least 115,000 years across both Homo sapiens and Neanderthal species (Hoffman et al., 2018b, Zilhão et al., 2010). Botha $(2008,2010)$ details the methodological reasoning researchers use to take a pierced shell to indicate complex language ability, and how it makes a number of inferential steps: that the pierced shells are indeed beads, the beads are indeed symbols, and the symbols denote complex language ability by their users. He describes the last part of this argument as especially flawed, in that it uses untenable assumptions, as the researchers do not establish an adequate linkage of the cognitive mechanisms to the material that this referential behaviour denotes. Botha also criticizes the mixed message in exactly what aspect of language is being indicated. Often 'complex language' and 'syntactic language' are those which are being inferred, while it is not explained why a syntax-less 'protolanguage' (Zywiczynski et al., 2017) or other simpler linguistic system would not suffice in a symbolling community. Wynn and Coolidge (2007) likewise criticize the idea that an inference from artefacts to cognition and language cannot be made without specifying what cognitive abilities were necessary in the making/using of these objects, and therefore what the symbolic behaviour exactly establishes. While Henshilwood and Dubrueil (2009, 2011) afford much closer attention to explaining cognitive mechanisms than is often the case, the additional issues in Table 1 maintain that the symbolic method of interpreting language and complex cognition is a problematic methodology, and a thorn in the side of the contribution of archaeology to the discipline of language evolution.

One way to circumvent these methodological difficulties, it is suggested here, is to find a highly correlated cognitive feature that might be more observable in the fossil record than language, and to look for evidence of its evolutionary prehistory instead. One cognitive correlate whose relationship with language has undergone much study over decades of research in education, medicine, comparative biology and psychology (Abu-Akel, 2003; Miller, 2006; Call and Tomasello, 2008; Carson et al., 2013), is that of theory of mind. Theory of mind is the cognitive ability for individuals to ascribe mental states to others (Wellman et al., 2001), such as their desires, intentions, knowledge and beliefs. Having a theory of mind is socially vital in human relationships, as it allows for a meeting of mental worlds. Once an individual can attribute others with like mental behaviours, a 'mindscape' is created where thoughts, feelings and knowledge can be shared and understood by others (Stade and Gamble, 
TABLE 2 As opposed to the issues detailed in Table 1, theory of mind as a proxy for language avoids a number of pitfalls.

\section{Benefit Detail}

Robust Mechanisms Theory of mind ability has a well-defined, predictive relationship with language ability (e.g. Miller, 20o6).

Broader Applications The use of theory of mind as a proxy does not limit interpretations to rare instances and recent timeframes, but can be applied throughout analyses of past social behaviour (e.g. Cole, 2015).

Greater Confidence Theory of mind might be better identifiable in the archaeological record as certain social behaviours are shown experimentally to require theory of mind (e.g. Remmel and Peters, 2009) and therefore evidence of these behaviours can be taken as evidence of the necessary underlying cognitive processes having been present.

Scaled Interpretation Theory of mind has levels of complexity that correlate with different features of language complexity (e.g. de Villiers and Pyers, 2002)

2019). New emotions which depend on reflecting on the thoughts of others, such as embarrassment or guilt, become possible (Oatley and Johnson-Laird, 1986). As Miller (2009) notes, those with a theory of mind can coordinate their behaviour with the actions of others, as well as tease, deceive, console, and cooperate based on notions of what others are thinking. The attainment of theory of mind therefore permits the very existence of the human social and emotional niche.

As a proxy for language ability, theory of mind avoids many of the pitfalls associated with symbolic inferences of cognition and language (Table 2). The fact that it has a similar complex developmental sequence to language (as opposed to the binary attribute of symbolism being present or absent) means it can offer a nuanced window, and imply not only the presence or absence of language, but the ability to ask 'how much' and 'what kind' of language is being implied. It also allows researchers to analyse behaviour further back in time than the Upper or Middle Palaeolithic, and gather crucial evidence about this important timeframe that is otherwise shrouded in a dearth of diversity in material culture compared to later periods. While using theory of mind as 
a proxy does not explain how language evolved, or why, it is an opportunity to understand crucially more about when.

\section{$2 \quad$ Theory of mind and language}

As others' minds are not directly accessible, humans infer the mental states of others by reasoning about these states (some mechanistic accounts use the word 'theorizing', which is where 'theory of mind' gets its name, although it has also been referred to as mentalizing, mind-reading and folk psychology). With this cognitive ability, an individual can characterize others, and themselves, as thinking agents with the understanding that individuals hold mental states, such as desires, intentions, knowledge and beliefs, which are independent from their own. Theory of mind is often assessed through a person's false belief understanding, that is, their demonstrating (usually linguistically, which raises its own methodological issues) that they realize that another individual holds a belief which they know to be false. This is because appreciating that someone holds a false belief reveals that they are ascribing others with thoughts, beliefs, intentions and desires that are separate from their own. False belief understanding is exhibited in typically developing children between the ages of three and four (Wellman et al., 2001), after a developmental trajectory involving the acquisition and progression of a number of other cognitive skills (Miller, 2006; Wellman, 2002). While early theory of mind understanding in children younger than three has been suggested (Onishi and Baillargeon, 2005), the issue is under debate (Powell et al., 2018).

Theory of mind in itself consists of levels of complexity, where thoughts are embedded in thoughts, called levels or orders of intentionality (Dennett, 1983). Basic theory of mind can be described as having two levels of intentionality, because it is where an individual ascribes thoughts to another individual (two levels of thoughts). Third-level intentionality, therefore, is where an individual ascribes thoughts that another has about someone else (three levels of thoughts), and so on (Fig. 1); first-level intentionality therefore includes no reasoning about the thoughts of others. Stiller and Dunbar (2007) showed how modern humans are thought to be able to attain a fourth- or fifth-level intentionality before it becomes too cognitively demanding, although O'Grady et al. (2015) demonstrated that adults can understand at least seven levels of intention embedding.

There has been a recent growing interest in theory of mind from the archaeological community (Mithen, 2005; Henshilwood and Dubrueil, 2009, 2011; Shipton, 2010; Cole, 2015, 2019; Wynn and Coolidge, 2016; Stade, 2017; Stade and 


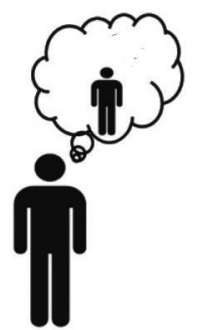

First level intentionality

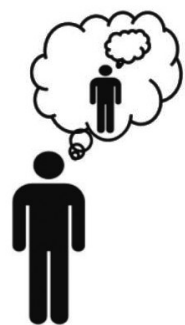

Second level intentionality

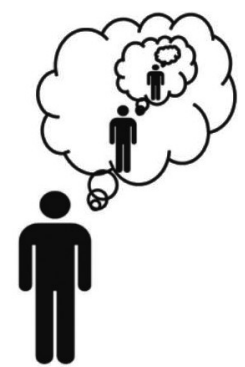

Third level intentionality

FIGURE 1 Levels of intentionality, where thoughts about another's thoughts can be embedded in a hierarchy of increasing complexity FROM STADE (2017)

Gamble, 2019), presumably since Robin Dunbar (1992) introduced a correlation between neocortex size and group size as a way to predict fossil hominin group size, and correlated it to the development of stages of theory of mind (Dunbar, 1998, 2004). Henshilwood and Dubrueil (2009, 2011) have even discussed theory of mind in regards to the symbolic behaviour inferred from archaeological material. They consider the importance of the evolution of theory of mind, but discount it as key to linking symbolic material to language as, "it is far from obvious that we need three, four, or five orders of intentionality to understand symbolic, artistic, or religious behaviour." (Henshilwood and Dubrueil, 2011: 364); here they consider theory of mind in relation to symbolism, instead of as a direct link to language itself, a position which this paper uniquely takes.

What makes theory of mind most attractive as a proxy for language ability is its close relationship to language, both developmentally and functionally (Astington and Baird, 2005; de Villiers, 2007). Language is fundamentally grounded in theory of mind, as "we cannot make sense of communicative interactions without presupposing that the interlocutors possess mutual knowledge of relevant beliefs and intentions" (Baldwin and Moses, 1994: 133). However, there is debate surrounding the order of their evolutionary development; specifically, whether language is necessary for a "fully-formed" theory of mind (Sperber and Wilson, 1986, Astington and Jenkins, 1999, Scott-Philips, 2015). Following Malle (2002), this author takes the view that they developed together (see Section 3). The pre-adaptations that support the development of theory of mind are many of the same abilities that allow for the acquisition of language, and the important role that the development of theory of mind has for language learning and 
TABLE 3 A developmental timeline of the first five years of childhood in terms of theory of mind and language acquisition in typically developing children

\begin{tabular}{ll} 
Age & Aspects of theory of mind and language \\
\hline 6-12 months & - Joint attention, including gaze and point following, and \\
& alternation of gaze between person and object \\
- & First words \\
13-24 months & Recognize intentionality in others as demonstrated in \\
& word use \\
- & Recognize that others have desires different from one's \\
& own \\
- & Early pretend play \\
- & Begin to use mental state terms with truly mentalistic \\
& functions \\
30-36 months & Increasingly sophisticated pretend play \\
- & Increasing ability to understand how things look from \\
& another's perspective \\
37-48 months & Begin to understand sentence complements \\
- & Consistently pass false-belief and appearance-reality \\
& tasks
\end{tabular}

ADAPTED FROM MILLER (2006)

vice versa has long been emphasized (e.g. Leslie, 1987; Astington and Pelletier, 1996). Table 3 contains a summary of the developmental overlaps between key stages in language and theory of mind development in typically developing children (Miller, 2006).

The relationship between language and theory of mind extends to the point that in standardized testing, theory of mind and language ability predict one another's scores, both in children and adults, whether typically developing, or in those with cognitive or physical impairments (Eisenmajer and Prior, 1991; Happé, 1995; Jenkins and Astington, 1996; Hughes and Dunn, 1997; Hughes, 1998; Cutting and Dunn, 1999; Astington and Jenkins, 1999; Courtin, 200o; Farrar and Maag, 2002; Ruffman et al., 2003; Slade and Ruffman, 2005; Tager-Flusberg and Joseph, 2005; de Villiers, 2005; Milligan et al., 2007; Schick et al., 2007; Farrar et al., 2009; Pyers and Senghas, 2009; Dahlgren et al., 2010; Rakhlin et al., 2011; Ebert, 2015; Brooks and Meltzoff, 2015; Grazzani et al., 2018). As an example, in a diverse study of deaf children, Schick et al. (2007) tested the language skills, non-verbal intelligence skills, and false belief ability of 176 deaf 
children aged three-to-eight years old, who used either American Sign Language or English to communicate with their parents. They wanted to examine if language affects children's theory of mind ability because the tasks demand it, because of how it affects other cognitive processes, or because it actually plays an important role in theory of mind development. They found that deaf children of hearing parents had a significant delay in theory of mind acquisition, whether or not the parents used American Sign Language to communicate with the child. Deaf children of hearing parents typically experience language delay, as they are normally not brought up in as rich a linguistic environment, due to less active and passive language input (Courtin, 200o). However, deaf children of deaf parents acquired false belief understanding at the same rate that hearing children do, presumably because they were exposed to as rich of a linguistic environment and community as hearing/oral children with hearing/oral parents. Schick et al. (2007) found that vocabulary, as well as syntactic complements, were significant predictors of theory of mind task success, and that across all groups, language was a significant predictor of their false belief score, which is often used to assess theory of mind ability. This is just one of many studies that shows a strong correlation between the two abilities, and stands as a strong illustration of the predictive relationship between language and theory of mind.

\section{3}

\section{A coevolution of theory of mind and language}

A number of studies similar to Schick et al. (2007) show the important role that theory of mind and language play in one another's development, and it is because of this intertwined relationship that some researchers have posited a coevolution of the two abilities (Corballis, 2012; Malle, 2002; Worden, 1998; Smith, 1996; Shatz, 1994; Woensdregt and Smith, 2017). Malle (2002) speaks of language and theory of mind as inseparable, and supports an "escalation process in which language and theory of mind have fuelled each other's evolution." (p. 265). It is possible to point out that while this relationship exists in modern humans, it is impossible to know the organization of, and relationships between, ancestral hominin species' cognitive structures. However, our cognitive evolution, like our physical evolution, is continuous with that of ancestral hominin species; our cognitive structures have emerged from these (or cousins of these) ancestral forms. As such, the organization of our minds should not be expected to be built on radically different organizational features, unless there exists some supporting evidence to lead us to that conclusion. That is why there is legitimacy in looking at the cognition of modern humans and hypothesizing 
backwards to the cognition of Palaeolithic hominins, who are only separated from modern humans by up to a few million years. Treating our species as distinct beyond cognitive comparison is to eject ourselves from the comparisons allowed for between other species and their ancestors. This is not to argue that Palaeolithic hominins were cognitively equivalent to moderns, or even that it could be likely; however, if cognitive relationships and features in the development in modern humans are found, then it is anticipated that Palaeolithic hominins possessed those relationships and connections between cognitive features too. The alternative to modern and past hominins having the same organizational principles between cognitive features would be, in order to have such a disjoint, that the slate had once been wiped clean and then developed anew. The focus here is particularly on the Lower Palaeolithic hominins, such as Homo erectus and Homo heidelbergensis: species where there is less support for sophisticated cognitive and linguistic abilities due to a fragmented material record (compared to more recent Neanderthal species who have had more focus as a potential linguistic species, e.g. Dediu and Levinson, 2013; Johansson, 2013). However, it is still considered prudent here to believe that the neu$\mathrm{ral} /$ functional organization of cognitive abilities, whatever their complexity, would be similar in relationship due to their common origin and evolutionary continuity with ourselves. While no claim is being made here yet about the language or theory of mind abilities of Lower Palaeolithic hominins, I do support that whatever the skill levels in these areas were, they can be assumed to have had the same intertwined developmental relationship as exists in modern humans today.

Added support for the coevolution of language and theory of mind might come from studies of non-human animal cognition and their correlation between these two abilities. Theory of mind seems to be exceptionally rarely demonstrated in non-human animals (Heyes, 1998; Gallagher and Frith, 2003; Horowitz, 2011), similarly to language skills except in language trained apes (Tomasello, 2017). However, certain skills involved in theory of mind have been evidenced in non-human species (Bugnyar et al., 2016, Krupenye et al., 2017). While it is true these animals do not have language, it is quite possible that they have certain symbolling or other pre-linguistic skills that do correlate to their incipient theory of mind abilities. Indeed, it is the species which show implicit theory of mind that tend to be the species with complex communication systems as well. Unfortunately, no such experiments exist that empirically compare individuals' theory of mind and language abilities. While primates have been taught to use elements of human language (Hixson, 1998), and are often subjects of experiments to assess their ability to use theory of mind (which indeed they sometimes seem to: Premack and Woodruff, 1978; Tomasello and 
Call, 1997; Penn and Povinelli, 2007; Call and Tomasello, 2008), these experimental research questions remain separate, and the scores are not used in relation to each other. One notable study, however, is Russell et al. (2011), in which the cognitive performance of apes reared in laboratory, zoo or sanctuary settings was compared to enculturated apes reared in an environment with abundant human interaction. The enculturated apes significantly outperformed the other group in physical cognition (11\%), but even more so in measures of social cognition $(32 \%)$, such as gaze following. While the battery of tests did not include non-verbal theory of mind tasks, it did suggest that the environment during development had a significant impact on their communicative and socio-cognitive abilities, and it was the enculturated apes, who were often language trained, who performed the best in tasks which utilized skills key to developing a theory of mind.

Another area that requires further research lies in the correlation in modern humans between more complex levels of theory of mind and language, as virtually all experiments focus on language according to the acquisition of secondlevel intentionality. Few studies like this exist, though those that do support that this correlation scales up beyond second-level intentionality (Lockl and Schneider, 2007; Miller, 2009), and also lasts into adulthood (O'Reilly et al., 2014).

\section{How much language?}

One of the strengths of using theory of mind as a proxy, which is not offered by symbolism, is that theory of mind co-develops with language along predictable stages in typical development (Table 3). Different stages of theory of mind that have been interpreted from the material record can then be correlated to the existence of certain aspects of linguistic complexity. When children acquire theory of mind between the ages of three and four, they are already able to use many linguistic functions (Leslie, 1987; Miller, 2006). But it seems that word reference, the ability to establish a word-object link inferred from the communicative behaviour of others (Baldwin, 1993), which allows for declarative joint attention (Sodian and Kristen-Antonow, 2015), is a key trait in the acquisition of knowledge that others have minds different from ones' own, and can therefore hold a false belief (Miller, 2006). Therefore, I argue that if a second-level theory of mind can be interpreted from materials and behaviours in the archaeological record, a most conservative estimate would be that the Palaeolithic communities possessing this level of theory of mind would also be in possession of a linguistic system that included words, i.e. a lexicon. 
A number of studies have shown that theory of mind abilities are supported by specific syntactic constructions like complementation (de Villiers and Pyers, 2002; Lohman and Tomasello, 2003; Hale and Tager-Flusberg, 2003; Schick et al., 2007), and semantic constructions like mental state verbs (Ruffman et al., 2002, Mayer and Trauble, 2013). While these seem like arbitrary linguistic phenomena to focus on, the linkage is made here because of the empirical connections pre-existing studies have made. Children acquire third-level theory of mind typically between the ages of five and six (Miller, 2009).Third-level intentionality implies the possession of more complex linguistic abilities, including the semantic labels and linguistic architecture to attribute mental states to others. These are skills that are developing during the acquisition of second-level intentionality, but are integral to the acquisition of third-level intentionality (Lockl and Schneider, 2007). This is why I suggest, again in a most conservative estimate, that archaeological evidence of the possession of a third-level theory of mind would also indicate the possession of grammatical structures such as complementation (where a linguistic constituent requires another to complement its meaning, Crystal, 1995), mental state verbs, and the linguistic structures to attribute mental states (which vary in different languages but always imply a certain grammatical organization).

These interpretive aspects of theory of mind as a proxy are perhaps its most powerful attribute, compared to the binary aspects that a symbolic proxy could offer for indicating language ability. With the entangled development of language and theory of mind, shared function, likely coevolution and nuanced interpretive value now illustrated, we can see how theory of mind can act as a proxy to indicate language ability in Palaeolithic hominin communities. However, the only way for this relationship to be useful is if we can recognize theory of mind in the archaeological record.

\section{$5 \quad$ Recognizing theory of mind in the archaeological record}

In considering how to recognize theory of mind in the archaeological record, at first glance it evinces the same problem as language: its ephemeral nature. Thoughts, after all, do not leave direct evidence in material form, just as an utterance disappears as soon as it has been spoken. But cognition affects behaviour, and behaviour does leave impressions of activity in the archaeological record, which can be reconstructed, including some cognitive aspects of that behaviour. Theory of mind is a necessary component of certain behaviours which require its complex cognitive potential. For one example, theory of mind is implicated in an important and pervasive feature of a very hominin abil- 
ity, which is that of complex cultural transmission (including imitation sensu stricto, Tomasello, 1996, and teaching, Strauss et al., 2002), to which the rich material culture of our species owes its persistence. Imitation is the replication of another's physical processes in order to complete a goal, and is very rare or non-existent in non-human species outside of the laboratory (Tomasello and Call, 1997; Whiten et al., 2009). Teaching, as in the intentional conferring of knowledge to another (Frye and Ziv 2004), is also unique to humans and is not recorded in other species (Strauss and Ziv, 2012; Kline, 2015). This is a mentalistic definition, and its uniqueness should not be surprising considering the rarity of examples of theory of mind ability in non-human species. Claims of teaching in non-human animals exist, but are likely a matter of definitions which base the identification of teaching on functional outcomes instead of mentalistic approaches (e.g. Musgrave et al., 2016). The identification of complex social learning to pass on sophisticated technological knowledge can therefore provide important insight into the cognitive behaviours at play in Palaeolithic communities, long before representational symbolic material culture was being created under just the right conditions to preserve in the material record.

Hominin stone tools present themselves as particularly important for those interested in minds for a number of reasons. Their abundance in the record is a 3.3-million-year testimony of human (and pre-human) cultural transmission. Being made of stone means that they have been preserved in many cases, while associated organic materials, presumably equally or more abundant in Palaeolithic communities, have disappeared due to varied taphonomic processes. Most importantly, stone tool technology is learned behaviour; stone tools represent the knowledge and skill that hominins used during the learning, creation, and the use of the artefact (Tostevin, 2012). While some researchers hypothesize that the reproduction of tool forms in the Lower Palaeolithic may have a biological input (Corbey et al., 2016), the vast majority of researchers see these forms as socially transmitted. Hosfield et al. (2018) list a number of reasons why Acheulean handaxes indeed resemble learned, cultural artefacts. They emphasize the morphological variation in handaxes that exists across both time and space, and the fact that while the general form of handaxes may be similar, to ignore the variations which do exist is to treat their forms too simplistically. Hosfield et al. also point out the absence of handaxe technology at certain sites and locations, which suggests that the creation of handaxes is the product of behavioural choice and population factors.

As handaxes are cultural objects, as are other lithic types and traditions, stone tools represent knowledge that individual makers have learned from others. As such, understanding their morphological patterns can lend insight into 
the cognitive processes that afforded their persistence. A number of studies, most of them conducted relatively recently, have investigated social learning in the context of stone knapping experiments (Ohnuma et al., 1997; Putt et al., 2014; Morgan et al., 2015, Schillinger et al., 2015; Lombao et al., 2017; Stade, 2017). Experimental studies like these can provide vital empirical data to make these important connections between materials and minds, and thus the stone tool record offers the highest potential for analysing artefacts for behaviours that require theory of mind, in this case complex social learning.

Social learning has also been investigated in archaeological material. Mithen (1999) argues that handaxes would have necessitated imitative skill in order for them to be manufactured, as do Wynn (1995), Shipton et al. (2009), Shipton (2010), and Lycett et al. (2015). Lycett et al. (2016a: 31) considered that the statistical patterns of variation seen between handaxe assemblages at different sites and regions would be explained by imitative replication, echoing the sentiment in Hosfield et al. (2018). Morgan et al. (2015) even suggested that earlier Oldowan core and flake technologies might have involved an imitative element, and the core reduction techniques found at some Oldowan sites were suggested in Stade (2017) to require the capacity to replicate the physical processes of others (imitation). Gärdenfors and Högberg (2017) see teaching 'by demonstration' (which might by this paper's definition constitute imitation) as requisite for Oldowan technologies to afford their stable cultural transmission. Conversely, Tennie et al. (2016) speaks of a "zone of latent solutions" where Oldowan and Acheulean technologies could be individually reinvented in a low-fidelity, emulative condition, not requiring complex social learning. To most authors then, the Acheulean contains elements that require imitation for its manufacture and persistence in the record, and support a social learning method that necessitates theory of mind. If theory of mind indeed coevolved alongside the linguistic abilities that scaffolded its development, this would support the contention that Acheulean communities were in possession of a certain level of linguistic competence, minimally a population capable of word reference, and the joint attention and symbolic capacity this necessitates. This also pushes back the date for the oft quoted 100,000 years of the emergence of language (Hornstein, 2008, Bolhuis et al., 2014, Tattersall, 2014, Wikipedia contributors, 2019), to 1.75 million years ago with the advent of Acheulean technology (Beyene et al., 2013). Being able to attribute species such as Homo erectus with these cognitive faculties is immensely constructive in painting a clearer picture of the behavioural and social potential of these important ancestral communities. While there is no strong evidence that Homo erectus populations created symbolic material culture, linguistic symbols themselves are referential, and through the transmission of their tools we can take an 
indirect route to the understanding of the symbolling potential of this species, despite a lack of artefactual indicators.

In terms of more complex social learning of the kind that requires intentionally conferring knowledge (teaching), Shennan and Steele (1999) have suggested that Acheulean technology might require active teaching in addition to imitation. However, the most often suggested technological form to require teaching is that with a predetermined core, such as Levallois technique (Schlanger, 1996; Lycett et al., 2016b). If so, complex theory of mind and the linguistic features correlated here such as mental state terms and complementation are features that arose at least by the Middle Palaeolithic (c. 300,000 years ago) in order for these more sophisticated technological features to be successfully transmitted and persist in populations. Stade (2017) suggests that certain technological features which appear even earlier in the record might suggest intentional teaching in order to be transmitted, and also shows through an experiment that a high level of standardization (or low morphological variability) might itself be a signature of complex social learning requiring teaching in the material record. If so, Lower Palaeolithic assemblages such as those at Boxgrove, UK (500,000 years ago), which feature very low morphological variability, and possibly opaque technological features such as tranchet flaking, might be such that these techniques needed to have been learned through high fidelity social learning methods as teaching, as imitation alone would not suffice for their prevalence. Stout et al. (2014) also considers technological features of Boxgrove such as platform preparation and the cognitive implications of this. What is perhaps now needed for future research is experimental evidence to stipulate which physical gestures and technological reasoning require imitation, and which are too 'opaque' and therefore require explicit teaching to be transmitted successfully. Other techniques/attributes that could be investigated further in the context of cultural transmission and required theory of mind are biface thinning, symmetry, and edge straightness (Shipton, 2018, Hutchence and Debackere, 2018).

A number of other aspects of hominin material culture could suggest complex theory of mind in the record (such as cultural conventions in the use of space or procurement of raw materials, fire technology, cooking, tool hafting, or adhesive manufacture). But because of issues of preservation in the record, lithic technology provides the best opportunity to detect theory of mind through complex social learning, and this is the reason for its emphasis and exploration here. 
The potential contribution that archaeology can offer the discipline of language evolution should not be underestimated. No other discipline deals with the physical materials made by the people for whom language and complex cognition were evolving (by definition). The extrapolations from behaviour to cognition that can be made through the study of these cultural materials allow us to venture inside the minds of our remote ancestors, and at first seem an unlikely challenge to be overcome. But through carefully structured and empirically supported chains of evidence, progress can be made in the discipline of cognitive archaeology, and the productive role of archaeology in language evolution can move forward. This article argues that the cultural transmission of stone tools requires high fidelity social learning that operates using theory of mind, of a kind that only develops in a linguistic environment. Theory of mind provides us with the linchpin to bridge materials and minds.

This paper does not suggest that the symbolic method of interpreting language and cognition should go the way of the 'symbolic revolution' which the archaeological record once seemed to suggest, and become an outdated model. Rather, novel, more explicit connections between minds and materials need to be synthesized in order for evolutionary linguistics and cognitive archaeology to progress, and produce new, fruitful ways to extract cognitive and linguistic information about our hominin ancestors' lives. Theory of mind has been presented here as a constructive way to identify these ancient linguistic abilities and track the evolution of this most human faculty. It addresses the question of "when", which is an important step to someday answering the "how" and "why" of language's origins.

\section{Acknowledgments}

I would like to thank a number of people for helpful comments on this manuscript, including Claudio Tennie, Ceri Shipton, Christian Hoggard and Iza Romanowska. This research did not receive any specific grant from funding agencies in the public, commercial, or not-for-profit sectors. 


\section{References}

Abu-Akel, A. 2003. A neurobiological mapping of theory of mind. Brain Research Reviews 43: 29-40. doi: 10.1016/so165-0173(o3)oo19o-5

Aiello, L.C. and Dunbar, R.I.M. 1993. Neocortex size, group size and the evolution of language. Current Anthropology 34: 184-193. doi: 10.1086/20416o

Aitchison, J. 2008. The Articulate Mammal: An Introduction to Psycholinguistics ( 5 th edition). London: Routledge.

Astington, J.W. and Baird, J.A. 2005. Why Language Matters for Theory of Mind. Oxford: Oxford University Press.

Astington, J.W., Jenkins, J.M. 1999. A longitudinal study of the relation between language and theory-of-mind development. Developmental Psychology 35: 1311-1320. doi: 10.1037//oo12-1649.35.5.1311

Astington, J.W. and Pelletier, J. 1996. The language of mind: Its role in teaching and learning. In D.R. Olson and N. Torrance (eds.), The handbook of education and human development: new models of learning, teaching and schooling, 593-619. Malden: Blackwell Publishing.

Baldwin, D.A. 1993. Infants' ability to consult the speaker for clues to word reference. Journal of Child Language 20: 395-418. doi: 10.1017/So305000900008345

Baldwin, D.A. and Moses, L.J. 1994. Early understanding of referential intent and attentional focus: evidence from language and emotion. In C. Lewis and P. Mitchell (eds.), Children's Early Understanding of Mind: Origins and Development, 133-156. Hove: Laurence Erlbaum Associates.

Beyene, Y., Katoh, S., WoldeGabriel, G., Hart, W.K., Uto, K., Sudo, M., Kondo, M., Hyodo, M., Renne, P.R., Suwa, G., and Asfaw, B. 2013. The characteristics and chronology of the earliest Acheulean at Konso, Ethiopia. PNAS 110: 1584-1591. doi: 10.1073/ pnas.1221285110

Bickerton, D. 20o9. Adam's Tongue: How Humans Made Language, How Language Made Humans. New York: Hill and Wang.

Bolhuis, J.J., Tattersall, I., Chomsky, N., and Berwick, R.C. 2014. How could language have evolved? PLoS Biology 12: e1001934. doi: 10.1371/journal.pbio.1001934

Botha, R. 2008. Prehistoric shell beads as a window on language evolution. Language and Communication 28: 197-212. doi: 10.1016/j.langcom.2007.05.002

Botha, R. 2010. On the soundness of inferring modern language from symbolic behaviour. Cambridge Archaeological Journal 20: 345-356. doi: 10.1017/So9597743100 00454

Brooks, R. and Meltzoff, A.N. 2015. Connecting the dots from infancy to childhood: A longitudinal study connecting gaze following, language, and explicit theory of mind. Journal of Experimental Child Psychology 130: 67-78. doi:10.1016/j.jecp.2014.o9 .010 
Bugnyar, T., Reber, S.A., and Buckner, C. 2016. Ravens attribute visual access to unseen competitors. Nature Communications 7: e10506. doi: 10.1038/ncomms1o5o6

Call, J., Tomasello, M. 2008. Does the chimpanzee have a theory of mind? 30 years later. Trends in Cognitive Sciences 12: 187-192. doi:10.1016/j.tics.2008.02.010

Carson, S.M., Koenig, M.A., Harms, M.B. 2013. Theory of Mind. WIREs Cognitive Science 4:391-402.

Chase, P.G. and Dibble, H.L. 1987. Middle Palaeolithic symbolism: A review of current evidence and interpretations. Journal of Anthropological Archaeology 6: 263-296. doi: 10.1016/0278-4165(87)90003-1

Christiansen, M.H. and Kirby, S. 1993. Language evolution: The hardest problem in science? In M.H. Christiansen and S. Kirby (eds.), Language Evolution, 1-15. Oxford: Oxford University Press.

Cole, J. 2015. Handaxe symmetry in the Lower and Middle Palaeolithic: Implications for the Acheulean gaze. In Coward, F., Hosfield, R., Pope, M. and Wenban-Smith, F. (eds.), Settlement, Society and Cognition in Human Evolution: Landscapes in Mind, 234-257. Cambridge: Cambridge University Press.

Cole, J. 2019. Knapping in the dark: Stone tools and a theory of mind. In K.A. Overmann and F.L. Coolidge (eds.), Squeezing Minds from Stones: Cognitive Archaeology and the Evolution of the Human Mind. Oxford: Oxford University Press.

Corballis, M.C. 2011. The Recursive Mind: The Origins of Human Language, Thought and Civilization. Princeton, New Jersey: Princeton University Press.

Corballis, M.C. 2012. The wandering mind: Mental time travel, theory of mind, and language. Análise Social 205: 870-893.

Corbey, R., Jagich, A., Vaesen, K., and Collard, M. 2016. The Acheulean handaxe: More like a bird's song than a Beatles' tune? Evolutionary Anthropology 25: 6-19. doi: 10.1002/evan.21467

Courtin, C. 200o. The impact of sign language on the cognitive development of deaf children: the case of theories of mind. Journal of Deaf Studies and Deaf Education 5 : 266-276. doi: 10.1093/deafed/5.3.266

Crystal, D. 1995. The Cambridge Encyclopedia of the English Language. Cambridge: Cambridge University Press.

Cutting, A.L., Dunn, J. 1999. Theory of mind, emotion understanding, language, and family background: Individual differences and interrelations. Child Development 70 : 853-865. doi: 10.1093/deafed/5.3.266

Dahlgren, S., Dahlgren Sandberg, A., and Larsson, M. 2010. Theory of mind in children with severe speech and physical impairments. Research in Developmental Disabilities 31: 617-624. doi: 10.1016/j.ridd.2009.12.010

Davidson, I. and Noble, W. 1989. The archaeology of perception: Traces of depiction and language. Current Anthropology 30: 125-155. doi: 10.1086/203723

Dediu, D. and Levinson, S.C. 2013. On the antiquity of language: The reinterpretation 
of Neanderthal linguistic capacities and its consequences. Frontiers in Psychology 4: 1-17. doi: 10.3389/fpsyg.2013.00397

d'Errico, F. 1998. Palaeolithic origins of artificial memory systems: An evolutionary perspective. In Renfrew, C. and Scarre C., (eds.), Cognition and Material Culture: The Archaeology of Symbolic Storage, 19-5o. Cambridge: McDonald Institute for Archaeological Research.

d'Errico, F., Henshilwood, C., Lawson, G., Vanhaeren, M., Tillier, A.-M., Soressi, M., Bresson, F., Maureille, B., Nowell, A., Lakarra, J., Backwell, L., and Julien, M. 2003. Archaeological evidence for the emergence of language, symbolism, and musican alternative multidisciplinary perspective. Journal of World Prehistory 17: 1-70. doi: 10.1023/A:1023980201043

d'Errico, F. and Nowell, A. 200o. A new look at the Berekhat Ram figurine: Implications for the origins of symbolism. Cambridge Archaeological Journal 10:123-167. doi: 10.1017/So959774300000056

de Villiers, J. 2005. Can language acquisition give children a point of view? In J.W. Astington and J.A. Baird (eds.), Why Language Matters for Theory of Mind, 186-219. New York: Oxford University Press.

de Villiers, J. 2007. The interface of language and theory of mind. Lingua 117: 1858-1878. doi: 10.1016/j.lingua.20o6.11.0o6

de Villiers, J. and Pyers J.E. 2002. Complements to cognition: A longitudinal study of the relationship between complex syntax and false-belief-understanding. Cognitive Development 17: 1037-106o. doi: 10.1016/So885-2014(02)ooo73-4

Dennett, D.C. 1983. Intentional systems in cognitive ethology: The "panglossian paradigm" defended. Behavioral and Brain Sciences 6: 343-355.

doi: 10.1017/So140525Xooo16393

Dunbar, R.I.M. 1992. Neocortex size as a constraint on group size in primates. Journal of Human Evolution 22: 469-493. doi:10.1016/0o47-2484(92)90o81-J

Dunbar, R.I.M. 1998. The social brain hypothesis. Evolutionary Anthropology 6: 178-19o. doi: $10.1002 /($ SICI)1520-6505

Dunbar, R.I.M. 2004. The Human Story: A New History of Mankind's Evolution. London: Faber and Faber.

Ebert, S. 2015. Longitudinal relations between theory of mind and metacognition and the impact of language. Journal of Cognition and Development 16: 559-586. doi: 10.108 o/15248372.2014.926272

Eisenmajer, R. and Prior, M. 1991. Cognitive linguistic correlates of 'theory of mind' ability in autistic children. British Journal of Developmental Psychology 9: 351-364. doi: 10.1111/j.2044-835X.1991.tboo882.X

Everett, D. 2017. How Language Began: The Story of Humanity's Greatest Invention. London: Profile Books.

Farrar, M.J. and Maag, L. 2002. Early language development and the emergence of a theory of mind. First Language 22: 197-213. doi: 10.1177/014272370202206504 
Farrar, M.J., Johnson, B., Tompkins, V., Easters, M., Zilisi-Medus, A., and Benigno, J.P. 2009. Language and theory of mind in preschool children with specific language impairment. Journal of Communication Disorders 42: 428-441. doi: 10.1016/j.jcomdis .2009.07.001

Frye, D. and Ziv, M. 2004. Children's understanding of teaching: The role of belief and knowledge. Cognitive Development 19: 457-477. doi: 10.1016/j.cogdev.2004.09.002

Gallagher, H.L. and Frith, C.D. 2003. Functional imaging of 'theory of mind'. Trends in Cognitive Sciences 7: 77-83. doi: 10.1016/S1364-6613(02)ooo25-6

Gärdenfors, P. and Högberg, A. 2017. The archaeology of teaching and the evolution of Homo docens. Current Anthropology 58: 188-208. doi: 10.1086/691178

Grazzani, I., Ornaghi, V., Conte, E., Pepe, A., and Caprin, C. 2018. The relation between emotion understanding and theory of mind in children aged 3 to 8: The key role of language. Frontiers in Psychology, 9(724): 1-10. doi: 10.3389/fpsyg.2018.00724

Hale C.M. and Tager-Flusberg, H. 2003. The influence of language on theory of mind: A training study. Developmental Science 6: 346-359. doi: 10.1111/1467-7687.00289

Happé, F.G.E. 1995. The role of age and verbal ability in the theory of mind task performance of subjects with autism. Child Development 66: 843-855. doi: 10.2307 $/ 1131954$

Henshilwood, C.S., d'Errico, F., Marean, C.W., Milo, R.G., and Yates, R. 20o1. An early bone tool industry from the Middle Stone Age at Blombos Cave, South Africa: Implications for the origins of modern human behaviour, symbolism and language. Journal of Human Evolution 41, 631-678. doi: 10.1006/jhev.2001.0515

Henshilwood, C.S., d'Errico, F., Vanhaeren, M., van Niekerk, K. and Jacobs, Z. 2004. Middle Stone Age shell beads from South Africa. Science 384-404. doi: 10.1126/science.10959०5

Henshilwood, C.S. and Dubrueil, B. 2009. Reading the artifacts: gleaning language skills from the Middle Stone Age in southern Africa. In Botha, R. and Knight, C. (eds.), The Cradle of Language, 41-61. Oxford: Oxford University Press.

Henshilwood, C.S. and Dubrueil, B. 2011. The Still Bay and Howiesons Poort, 77-59 ka: Symbolic material culture and the evolution of the mind during the African Middle Stone Age. Current Anthropology 52: 361-40o. doi: 10.1086/660o22

Heyes, C.M. 1998. Theory of mind in nonhuman primates. Behavioral and Brain Sciences 21: 101-148. doi: 10.1017/So140525X98000703

Hixson, M.D. 1998. Ape language research: A review and behavioural perspective. The Analysis of Verbal Behavior 15: 17-39. doi: 10.1007/BFo3392921

Hoffman, D.L., Standish, C.D., García-Diez, M., Pettitt, P.B., Milton J.A., Zilhão, J., Alcolea-González, J.J., Cantalejo-Duarte, P., Collado, H., de Balbín, R., Lorblanchet, M., Ramos-Muñoz, J., Weniger, G.-Ch., and Pike, A.W.G. 2018a. U-Th dating of carbonate crusts reveals Neandertal origin of Iberian cave art. Science 359: 912-915. doi: 10.1126/science.aap 7778 
Hoffman, D.L., Angelucci, D.E., Villaverde, V., Zapata, J., and Zilhão, J., 2018b. Symbolic use of marine shells and mineral pigments by Iberian Neanderthals 115,000 years ago. Science Advances 4: eaar5255. doi: 10.1073/pnas.0914088107

Hornstein, N. 2008. A Theory of Syntax: Minimal Operations and Universal Grammar. Cambridge: Cambridge University Press.

Horowitz, A. 2011. Theory of mind in dogs? Examining method and concept. Learning and Behavior 39: 314-317. doi: 10.3758/s13420-011-0041-7

Hosfield, R., Cole, J. and McNabb, J. 2018. Less of a bird's song than a hard rock ensemble. Evolutionary Anthropology 27: 9-20. https://doi.org/10.1002/evan.21551

Hughes, C. 1998. Executive function in pre-schoolers: Links with theory of mind and verbal ability. British Journal of Developmental Psychology 16: 233-253.

Hughes, C. and Dunn, J. 1997. "Pretend you didn't know": Pre-schoolers talk about mental states in pretend play. Cognitive Development 12: 477-499. doi: 10.1111/j.2044835X.1998.tboog21.X

Hutchence, L. and Debackere, S. 2018. An evaluation of behaviours considered indicative of skill in handaxe manufacture. Lithics 39: 36-51.

Jackendoff, R. 2002. Foundations of Language: Brain, Meaning, Grammar, Evolution. Oxford: Oxford University Press.

Jenkins, J.M. and Astington, J.W. 1996. Cognitive factors and family structure associated with theory of mind development in young children. Developmental Psychology 32: $70-78$.

Johansson, S. 2011. Constraining the time when language evolved. Linguistic and Philosophical Investigations 10: 45-59.

Johansson, S. 2013. The talking Neanderthals: What do fossils, genetics and archaeology say? Biolinguistics 7: 35-74.

Kline, M.A. 2015. How to learn about teaching: An evolutionary framework for the study of teaching behaviour in humans and other animals. Behavioral and Brain Sciences 38: 1-71. doi: 10.1017/So140525X1400oo9o

Krupenye, C., Kano, F., Hirata, S., Call, J., and Tomasello, M. 2017. A test of the submentalizing hypothesis: Apes' performance in a false belief task inanimate control. Communicative \& Integrative Biology 10: e1343771. doi:10.1080/19420889.2017.1343771

Leslie, A.M. 1987. Pretense and representation: The origins of "theory of mind". Psychological Review, 94: 412-426. doi: 10.1037/0033-295X.94.4.412

Lieberman, P. 2015. Language did not spring forth 100,ooo years ago. PLoS Biology 13: e1002064. doi: 10.1371/journal.pbio.1002064

Lockl, K. and Schneider, W. 2007. Knowledge about the mind: links between theory of mind and later metamemory. Child Development 78: 148-167. doi: 10.1111/j.14678624.2007.00990.x

Lohman, H. and Tomasello, M. 2003. The role of language in the development of false belief understanding: A training study. Child Development 74: 1130-1144. doi: $10.1111 / 1467-8624.00597$ 
Lombao, D., Guardiola, M., Mosquera, M. 2017. Teaching to make stone tools: New experimental evidence supporting a technological hypothesis for the origins of language. Scientific Reports 7: 1-14. doi:10.1038/s41598-017-14322-y

Lycett, S.J., Schillinger, K., Kempe, M., and Mesoudi, A. 2015. Learning in the Acheulean: experimental insights using handaxe form as a 'model organism'. In A. Mesoudi \& K. Aoki (eds.), Learning Strategies and Cultural Evolution during the Palaeolithic, 155166. Springer Japan.

Lycett, S.J., Schillinger, K., Eren, M., von Cramon-Taubadel, N., and Mesoudi, A. 2016a. Factors affecting Acheulean handaxe variation: Experimental insights, microevolutionary processes, and macroevolutionary outcomes. Quaternary International 411: 386-401. doi: 10.1016/j.quaint.2015.08.021

Lycett, S.J., von Cramon-Taubadel, N., and Eren, M.I. 2016b. Levallois: Potential implications for learning and cultural transmission capacities. Lithic Technology 41: 19-38. doi: 10.1179/2051618515Y.oooooooo12

Malle, B.F. 2002. The relation between language and theory of mind in development and evolution. In T. Givón and B.F. Malle (eds.), The Evolution of Language out of Pre-language, 265-284. Amsterdam: Benjamins.

Marshack, A. 1976. Some implications of the Palaeolithic symbolic evidence for the origin of language. Annals of the New York Academy of Sciences 280: 289-311. doi: $10.1086 / 201716$

Mayer, A. and Trauble, B.E. 2013. Synchrony in the onset of mental state understanding across cultures? A study among children in Samoa. International Journal of Behavioral Development 37: 21-28. doi: 10.1177/0165025412454030

Miller, C.A. 2006. Developmental relationships between language and theory of mind. American Journal of Speech Language Pathology 15: 142-154. doi: 10.1044/1058-036o (2006/014)

Miller, S.A. 20og. Children's understanding of second-order mental states. Psychological Bulletin 135: 749-773. doi: 10.1037/aoo16854

Milligan, K., Astington, J.W., and Dack, L.A. 2007. Language and theory of mind: Metaanalysis of the relation between language ability and false-belief understanding. Child Development 78: 622-646. doi: 10.1111/j.1467-8624.2007.01018.x

Mithen, S. 1999. Imitation and cultural change: a view from the Stone Age, with special reference to the manufacture of handaxes. In H.O. Box and K.R. Gibson (eds.), Mammalian social learning: Comparative and ecological perspectives, 389-399. Cambridge: Cambridge University Press.

Mithen, S. 2005. Introduction. In S. Mithen (ed.), Creativity in Human Evolution and Prehistory, 1-11. New York: Routledge.

Moncel, M.-H., Chiotti, L., Gaillard, C., Onoratini, G., and Pleurdeau, D. 2012. Nonutilitarian lithic objects from the European Palaeolithic. Archaeology Ethnology \& Anthropology of Eurasia 40: 24-40. doi: 10.1016/j.aeae.2012.05.004 
Morgan, T.J.H., Uomini, N., Rendall, L.E., Chouinard-Thuly, L., Street, S.E., Lewis, H.M., Cross, C.P., Evans, C., Kearney, R., de la Torre, I., Whiten, A., and Laland, K.N. 2015. Experimental evidence for the co-evolution of hominin tool-making, teaching and language. Nature Communications 6: 1-8. doi: 10.1038/ncomms7029

Musgrave, S., Morgan, D., Lonsdorf, L., Mundry, R., and Sanz C. 2016. Tool transfers are a form of teaching in chimpanzees. Nature: Scientific Reports 6: 34783. doi: $10.1038 /$ srep34783

Noble, W. and Davidson, I. 1991. The evolutionary emergence of modern human behaviour: Language and its archaeology. Man 26: 223-253. doi: 10.2307/280383o

Oatley, K. and Johnson-Laird, P.N. 1986. Towards a cognitive theory of emotions. Cognition and Emotion 1: 29-5o. doi: 10.1080/o2699938708408362

O'Grady, C., Kliesch, C., Smith, K., and Scott-Phillips, T.C. 2015. The ease and extent of recursive mindreading, across implicit and explicit tasks. Evolution and Human Behavior 36: 313-322. doi: 10.1016/j.evolhumbehav.2015.01.004

Ohnuma, K., Aoki, K., and Akazawa, T. 1997. Transmission of tool-making through verbal and non-verbal communication: Preliminary experiments in Levallois flake production. Anthropological Science 105: 159-168. doi: 10.1537/ase.105.159

Onishi, K.H. and Baillargeon, R. 2005. Do 15-month-old infants understand false beliefs? Science 308: 255-258. doi: 10.1126/science.1107621

O'Reilly, K., Peterson, C.C., and Wellman, H.M. 2014. Sarcasm and advanced theory of mind understanding in children and adults with prelingual deafness. Developmental Psychology 50: 1862-1877. doi: 10.1037/aoo36654

Penn, D.C. and Povinelli, D.J. 2007. On the lack of evidence that non-human animals possess anything remotely resembling a 'theory of mind'. Philosophical Transactions of the Royal Society B 362: 731-744. doi: 10.1098/rstb.2006.2023

Powell, L.J., Hobbs, K., Bardis, A., Carey, S., and Saxe, R. 2018. Replications of implicit theory of mind tasks with varying representational demands. Cognitive Development 78:1265-1287. doi: 10.1016/j.cogdev.2017.10.004

Premack, D. and Woodruff, G. 1978. Does the chimpanzee have a theory of mind? Behavioral and Brain Sciences 1978: 515-526. doi: 10.1017/So140525Xooo76512

Půtová, B. 2016. Proto-Art: The origins of non-utilitarian symbolic thinking and artistic creativity. Anthropologie 54: 175-185.

Putt, S.S., Woods A.D., and Franciscus R.G. 2014. The role of verbal interaction during experimental bifacial stone tool manufacture. Lithic Technology 39: 96-112. doi: 10.1179/o197726114Z.ooooooooo36

Pyers, J.E. and Senghas, A. 20o9. Language promotes false-belief understanding: Evidence from learners of a new sign language. Psychological Science 20: 805-812. doi: 10.1111/j.1467-9280.2009.02377.X

Rakhlin, N., Kornilov, S.A., Reich, J., Babyonyshev, M., Koposov, R.A., Grigorenko, E.L. 2011. The relationship between syntactic development and theory of mind: Evidence 
from a small-population study of a developmental language disorder. Journal of Neurolinguistics 24: 476-496. doi: 10.1111/j.1467-9280.2009.02377.x

Remmel, E., and Peters, K. 2009. Theory of mind and language in cochlear implants. Journal of Deaf Studies and Deaf Education 14: 218-236. doi: 10.1093/deafed /enno36

Ruffman, T., Slade, L., and Crowe, E. 2002. The relation between children's and mothers' mental state language and theory of mind understanding. Child Development 73 : 734-751. doi: 10.1111/1467-8624.00435

Ruffman, T., Slade, L., Rowlandson, K., Rumsey, C., and Garnham, A. 2003. How language relates to belief, desire and emotion understanding. Cognitive Development 18: 139-158. doi: 10.1016/So885-2014(o3)oooo2-9

Russell, J.L., Lyn, H., Schaeffer, J.A., Hopkins, W.D. 2011. The role of socio-communicative rearing environments in the development of social and physical cognition in apes. Developmental Science 14: 1459-1470. doi.org: 10.1111/j.1467-7687.2011.0109o.x

Schick, B., de Villiers, P., de Villiers, J., and Hoffmeister, R. 2007. Language and theory of mind: A study of deaf children. Child Development 78: 376-396. doi: 10.1111/j.14678624.2007.01004.X

Schillinger, K., Mesoudi, A., and Lycett, S.J. 2015. The impact of imitative versus emulative learning mechanisms on artifactual variation: Implications for the evolution of material culture. Evolution and Human Behavior 36: 446-455. doi: 10.1016/j.evolhumbehav.2015.04.003

Schlanger, N. 1996. Understanding Levallois: Lithic technology and cognitive archaeology. Cambridge Archaeological Journal 6: 231-254. doi: 10.1017/So959774300001724

Scott-Phillips, T.C. 2015. Speaking our Minds. London: Red Globe Press.

Shatz, M. 1994. A Toddler's Life: Becoming a Person. New York: Oxford University Press.

Shennan, S. and Steele, J. 1999. Cultural learning in hominids: A behavioural ecological approach. In: H. Box and K. Gibson (Eds.) Mammalian Social Learning. Symposia of the Zoological Society of London 70: $367-388$. Cambridge: Cambridge University Press.

Shipton, C., Petraglia, M., and Paddayya, K. 20og. Inferring aspects of Acheulean sociality and cognition in biface technology. In B. Adams and S. Blades (eds.), Lithic Materials and Palaeolithic Societies, 219-231. Chichester: Wiley-Blackwell.

Shipton, C. 2010. Imitation and shared intentionality in the Acheulean. Cambridge Archaeological Journal 20: 197-210. doi: 10.1017/So959774310000235

Shipton, C. 2018. Biface skill in the East African Acheulean: Progressive trends and random walks. African Archaeological Review 35: 107-131. doi: 10.1007/s10437-018 $-9287-1$

Slade, L., Ruffman, T. 2005. How language does (and does not) relate to theory of mind: A longitudinal study of syntax, semantics, working memory and false belief. British Journal of Developmental Psychology 23: 117-141. doi: 10.1348/026151004X21332 
Smith, P.K. 1996. Language and the evolution of mind-reading. In P. Carruthers \& P.K. Smith (eds.), Theories of theories of mind, 344-354. Cambridge: Cambridge University Press.

Sodian, B., Kristen-Antonow, S. 2015. Declarative joint attention as a foundation of theory of mind. Developmental Psychology 51: 1190-1200.

Sperber, D. and Wilson, D. 1986. Relevance: Communication and Cognition. Oxford: Blackwell Publishing, ist edition.

Stade, C. 2017. Lithic Morphological Variability as a Proxy for Palaeolithic Linguistic Ability: A Knapping Training Study Exploring Cultural Transmission, Theory of Mind and Language. University of Southampton, PhD Thesis.

Stade, C. and Gamble, C. 2019. In three minds: extending cognitive archaeology with the social brain. In K.A. Overmann \& F.L. Coolidge (eds.), Squeezing Minds from Stones: Cognitive Archaeology and the Evolution of the Human Mind, 319-331. Oxford: Oxford University Press.

Stiller, J. and Dunbar, R.I.M. 2007. Perspective-taking and memory capacity predict social network size. Social Networks 29: 93-104. doi: 10.1016/j.socnet.2006.04 .001

Stout, D., Apel, J., Commander, J., and Roberts, M. 2014. Late Acheulean technology and cognition at Boxgrove, U K. Journal of Archaeological Science 41, 576-59o. doi: 10.1016/j.jas.2013.10.001

Strauss, S., Ziv, M., and Stein, A. 2002. Teaching as a natural cognition and its relations to preschoolers' developing theory of mind. Cognitive Development 17: 1473-1487. doi: 10.1016/So885-2014(O2)oo128-4

Strauss, S. and Ziv, M. 2012. Teaching is a natural cognitive ability for humans. Mind, Brain and Education 6: 186-196. doi: 10.1111/j.1751-228X.2012.01156.x

Tager-Flusberg, H. and Joseph, R.M. 2005. How language facilitates the acquisition of false-belief understanding in children with autism. In J.W. Astington and J.A. Baird (eds.), Why Language Matters for Theory of Mind, 298-318. New York: Oxford University Press.

Tattersall, I. 2014. An evolutionary context for the emergence of language. Language Sciences 46: 199-206. doi: 10.1016/j.langsci.2014.06.o11

Tattersall, I. 2017. The material record and the antiquity of language. Neuroscience and Behavioral Reviews 81: 247-254. doi: 10.1016/j.neubiorev.2017.01.043

Tennie, C. Braun, D.R., Premo, L.S., and McPherron, S.P. 2016. The island test for cumulative culture in the Palaeolithic. In M.N. Haidle, N. Conard, and M. Bolus (eds.), The Nature of Culture: Based on an Interdisciplinary Symposium 'The Nature of Culture,' Tübingen, Germany, 121-133. Dordrecht: Springer.

Tomasello, M. 1996. Do apes ape? In C.M. Heyes and B.G. Galef (eds.), Social Learning in Animals: The Roots of Culture, 319-346. New York: Academic Press.

Tomasello, M. 2017. What did we learn from the ape language studies? In Hare, B. and 
Yamamoto, S. (eds.), Bonobos: Unique in Mind, Brain and Behavior, 95-104. Oxford: Oxford University Press.

Tomasello. M. and Call, J. 1997. Primate Cognition. New York: Oxford University Press. Tostevin, G. 2012. Seeing Lithics: A Middle-Range Theory for Testing for Cultural Transmission in the Pleistocene. American School of Prehistoric Research Monograph Series, Peabody Museum, Harvard University and Oxbow Books (Oxford, UK and Oakville, от).

Watts, I. 2009. Red ochre, body painting, and language: Interpreting the Blombos ochre. In Botha, R. and Knight, C. (eds.), The Cradle of Language, 62-92. Oxford: Oxford University Press.

Wellman, H.M. 2002. Understanding the psychological world: Developing a theory of mind. In: U. Goswami (ed.), Blackwell handbook of childhood cognitive development, 167-187. Blackwell handbooks of developmental psychology. Malden: Blackwell.

Wellman, H.M., Cross, D., and Watson, J. 20o1. Meta-analysis of theory-of-mind development: the truth about false belief. Child Development 72: 655-684. doi: 10.1111/14678624.00304

Whitehead, A.N. 1927. Symbolism: Its meaning and effect. New York: Fordham University Press.

Whiten, A., McGuigan, N., Marshall-Pescini, S., and Hopper, L. 20o9. Emulation, imitation, and over-imitation and the scope of culture for child and chimpanzee. Philosophical Transactions of the Royal Society B 364: 2417-2428. doi: 10.1098/rstb.2009 .0069

Wikipedia contributors. 2019. Origin of language. In Wikipedia, The Free Encyclopedia. https://en.wikipedia.org/w/index.php?title=Origin_of_language\&oldid=921758382 (Accessed: 05 August 2019).

Woensdregt, M., Smith, K. 2017. Pragmatics and language evolution. In Aronoff, M. (ed.), Oxford Research Encyclopedia of Linguistics. Oxford: Oxford University Press. doi: 10.1093/acrefore/9780199384655.013.321

Worden, R. 1998. The evolution of language from social intelligence. In J.R. Hurford, M. Studdert-Kennedy \& C. Knight (eds.), Approaches to the Evolution of Language, 148-166. Cambridge: Cambridge University Press.

Wynn, T. 1995. Handaxe enigmas. World Archaeology: 27, 10-24. doi: 10.1080/oo438243 .1995 .9980290

Wynn, T., Coolidge, F.L. 2007. Did a small but significant enhancement in workingmemory capacity power the evolution of modern thinking? In P. Mellars, K. Boyle, O. Bar-Yosef, and C. Stringer (eds.), Rethinking the Human Revolution: New Behavioural and Biological Perspectives on the Origin and Dispersal of Modern Humans, 79-9o. Cambridge: McDonald Institute for Archaeological Research.

Wynn, T. and Coolidge, F.L. 2010. Beyond symbolism and language. Current Anthropology 51: $\mathrm{S}_{5}-\mathrm{S} 16$. doi: 10.1086/650526 
Wynn, T. and Coolidge, F.L. 2016. Archaeological insights into hominin cognitive evolution. Evolutionary Anthropology 25: 200-213. doi: 10.1002/evan.21496

Wynn, T., Coolidge, F.L., and Bright, M. 20og. Hohlenstein-Stadel and the evolution of human conceptual thought. Cambridge Archaeological Journal 19: 73-84. doi: 10.1017/So959774309000043

Zilhão, J., Angelucci, D.E., Badal-García, E., d'Errico, F., Daniel, F., Dayet, L., Douka, K., Higham, T.F.G., Martínez-Sánchez, M.J., Montes-Bernárdez, R., Murcia-Mascarós, S., Pérez-Sirvent, C., Roldán-García, C., Vanhaeren, M., Villaverde, V., Wood, R., and Zapata, J. 2010. Symbolic use of marine shells and mineral pigments by Iberian Neandertals. PNAS 107: 1023-1028. doi:10.1073/pnas.0914088107

Zywiczynski, P., Gontier, N., and Wacewicz, S. 2017. The evolution of (proto-)language: Focus on mechanisms. Language Sciences 63: 1-11. doi: 10.1016/j.langsci.2017.06.004 